\title{
The Determinants of the Use of Oral Health Care Services by Consumers in West Africa: The Case of Senegal
}

\section{Lo Cheikh Mouhamadou Mbacke ", Diop Mbathio, Faye Daouda, Kanoute Aida, Diouf Massamba, Cisse Daouda}

Department of Public Health Faculty of Medicine University Cheikh Anta Diop of Dakar, Dakar, Senegal

\section{Email address:}

cheikhlo54@yahoo.fr (Lo C. M. Mbacke)

${ }^{*}$ Corresponding author

\section{To cite this article:}

Lo Cheikh Mouhamadou Mbacke, Diop Mbathio, Faye Daouda, Kanoute Aida, Diouf Massamba, Cisse Daouda. The Determinants of the Use of Oral Health Care Services by Consumers in West Africa: The Case of Senegal. Science Journal of Public Health.

Vol. 4, No. 6, 2016, pp. 445-450. doi: 10.11648/j.sjph.20160406.15

Received: September 7, 2016; Accepted: September 21, 2016; Published: October 11, 2016

\begin{abstract}
The purpose of this study is to identify the determinants in the resort to oral health care by the Senegalese populations. To achieve this, we have carried out a transversal descriptive study. Our results show that the patients living less than 5 kilometers away or between 5 and 10 kilometers away from the nearest health care facilities go more to the public dental ones than to the other types of facilities, with respectively $15 \%$ and $26 \%$. People who have no source of income or only one source of income tend to go to public dental facilities with respectively $17 \%$ and $34 \%$. In all the study population, $38 \%$ of the people go to the public dental facilities and pay themselves for the care fees, whereas only $12.5 \%$ go to the public dental facilities and have a mutual health insurance. The distance between the living place and the heath care facility, the type of job, the level of education, the monthly income and the type of medical care, are the factors that influence Senegalese people's use of oral health care services.
\end{abstract}

Keywords: Determinants, Use, Oral Health Care, Africa, Senegal

\section{Introduction}

In 2011, the consumption of care and medical goods in France was estimated at 178.9 billion euros, which places France in the third position behind the United States of America and the Netherlands, whereas Senegal and the other West African countries are lagging far behind [1].

Public health care spending per capita and per year in some West African countries is estimated at 3.5 dollars (USD) in Guinea, 8 in Côte d'Ivoire, 5 in Ghana, 9 in Mali whereas the standard figure of the World Health Organization is 13 USD [2].

The attention of the public health officials of these countries has been drawn by the low access to health care which derives from such factors as the cost related to the choice of the health care provider, the large discrepancy between rural and urban areas in terms of medical care expenses, work environment and welfare system.

Senegal is a perfect illustration of the troubles faced by these countries: increasing urbanization accounts for the positive evolution of the health indicators; remote rural areas accumulate the handicaps and see the slow evolution of their situation; and, finally, social welfare is not well developed yet [3]. As a result, populations highly renounce the use of health care services.

As a matter of fact, resorting to health care in general, and to oral health care in particular, has been a source of debate in Senegal since the last century. This is mainly due to the fact that the high rate of dental caries within the populations ranks fourth in the world's scourges [4].

In addition, renouncing health care is a complex phenomenon, which partly refers to "the non-resort to health care" and "the unmet health care needs". These two closely related notions are also discussed in the literature about health social inequalities. Renouncing health care is of course accounted for by people's resources; but it also turns out to be dependent on their representations and experiences regarding their potential recourse to dentistry [5]. Consequently, the profile of the consumer is defined as being 
the overall characteristics of an individual, on the basis of financial, socio-economic and geographical reasons.

The profile of the Senegalese consumer of oral health care varies in accordance with many considerations, but what remains rather unknown is the identification of the different factors that determine the consumption of dental care. As a result, this study was carried out to implement a strategy for a more equitable consumption.

\section{Methodology}

\subsection{The Study Framework}

The study was conducted in Senegal, a country located in the westernmost part of West Africa, and is the fourth economic power of the region with a GDP per capita of 1046.59 USD in 2013. Initially planned at a nationwide level, this study was finally restricted to the region of Dakar, the capital city, which concentrates about $2 / 3$ of the public dental facilities, and $3 / 4$ of the private ones. The Dakar region comprises four departments: Dakar, Pikine, Rufisque and Guediawaye.

\subsection{Targeted et Population}

Patients of the public as well as the private dental health facilities were targeted by the study.

\subsection{Inclusion Criteria}

All patients who come for a consultation or an appointment in the above targeted dental units, and who accept to participate in the study (a consent form was signed by all participants).

\subsection{Sample Size}

In the Dakar region, there are 74 public dental facilities and 140 private ones identified by the Ministry of Public Health and Welfare. We have chosen 12 facilities to conduct our survey, 6 public and 6 private ones; and they obey the following distribution: 3 public and 3 private facilities in the department of Dakar, which concentrates $75 \%$ of the dental facilities of all the Dakar region; 3 public and 3 private ones in the other departments: Guediawaye $(1$ public and 1 private), Pikine (1 public and 1 private) and Rufisque (1 public and 1 private).

For the patients of the survey, we have fixed the number at 600 , taking into account the low level of visitations in the private facilities. As a result, 80 patients out of 100 are chosen from the public facilities and 20 from the private ones, corresponding to $1 / 5$ of the patients of the survey in the private sector. The other patients are chosen from the public sector.

To sum up: 480 patients were questioned in the public dental facilities whereas only 120 patients were questioned in the private ones.

\subsection{Sampling Method}

For the recruitment of the statistical units, a two-stage random survey was carried out.

\subsubsection{First-Stage Sampling}

The sampling consisted in selecting at random 12 public and private dental facilities for the survey. The facilities were selected by means of a draw in two different boxes, the one containing the public dental facilities, and the other the private dental ones, for each department.

The basis of the survey was constituted by the facilities that are in the list of Ministry of Public Health and Welfare with all its identifiers.

\subsubsection{Second-Stage Sampling}

This sampling was about the selection of the patients in the different above named facilities. It was based on a step of 2 , right at the beginning of the consultations; which means that the first patient who arrived was chosen but the following patients were the $3 \mathrm{rd}$ and the 5 th, and so on and so forth until the required number of patients was reached. The patients who met the selection criteria were questioned, and so on until the number of patients in the selected facilities was reached.

\subsection{Survey Conduct}

Before the beginning of the survey, the questionnaire was tested and validated on some patients at the Dentistry Department. Our survey lasted four weeks during which the patients were questioned according to a questionnaire comprising several indicators. We were in the public facilities from $8 \mathrm{am}$ to $4 \mathrm{pm}$ and in the private ones from 8 am to $6 \mathrm{pm}$. We worked in close collaboration with the secretaries who managed the files of the patients who came for a consultation or for an appointment.

\subsection{Survey Parameters}

\section{Geographical Accessibility}

Accessibility to dental facilities was appreciated on the basis of the distance separating the patients' living places from the nearest medical facility.

\subsection{Financial Accessibility}

It was appreciated on the basis of the source of income and of the monthly income.

\subsection{Social and Economic Status}

The social and economic level was estimated according to several indicators such as: level of education, occupation, monthly income and type of care.

\subsection{Data Analysis}

At the end of the survey with the collected data, Microsoft WORD was used for data entry, EXCEL for realization of tables and figures and SPSS software for data entry and data processing. Some variables were cross-tabulated the ones with the others. 


\section{Results}

\subsection{Resort to Care According to the Distance Separating Home and the Dental Service}

We notice that in the population, the most representative

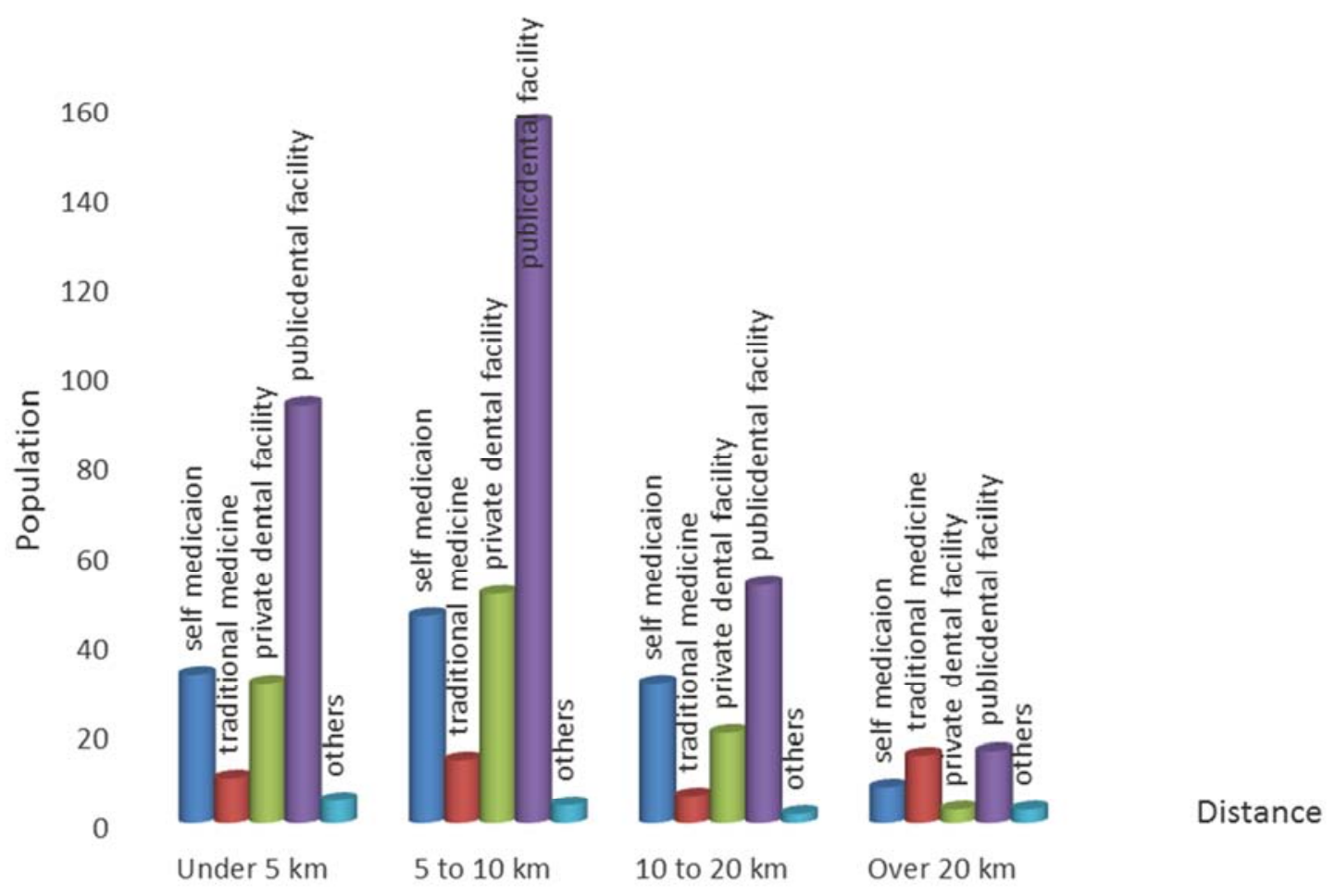

Fig. 1. Resort to care according to the distance between home and the dental service.

\subsection{Use of Health Care Services According to the Source of Income}

In our specific sample, we notice that the individuals who have no source of income, or only one source of income, tend to go to public dental facilities, with respectively $17 \%$ and $34 \%$ (table 1).

Table 1. Use of care services according to the source of income.

\begin{tabular}{lllll}
\hline Source of income & None & One & Two & Three and more \\
\cline { 1 - 4 } Recourse & 37 & 77 & 1 & 0 \\
\hline Self-medication & 12 & 33 & 1 & 1 \\
Traditional medicine & 102 & 203 & 12 & 2 \\
Public dental facility & 19 & 53 & 22 & 12 \\
Private dental facility & 5 & 8 & 0 & 0 \\
Others & 175 & 374 & 36 & 15 \\
Total & & & & \\
\hline
\end{tabular}

\subsection{Use of Care Services According to Monthly Income}

Patients whose monthly income is lower than 50,000 frs CFA ( $1 \mathrm{frs}$ CFA=655.55556) or is between 50,000 frs CFA and 100,000 frs CFA, go to public dental facilities, with respectively $21 \%$ and $21.5 \%$ (Fig. 2 ). values are the patients who go to public dental facilities and who live less than 5 kilometers away or between 5 and 10 kilometers away from the nearest health facility with respectively $15 \%$ and $26 \%$ (Fig. 1) 


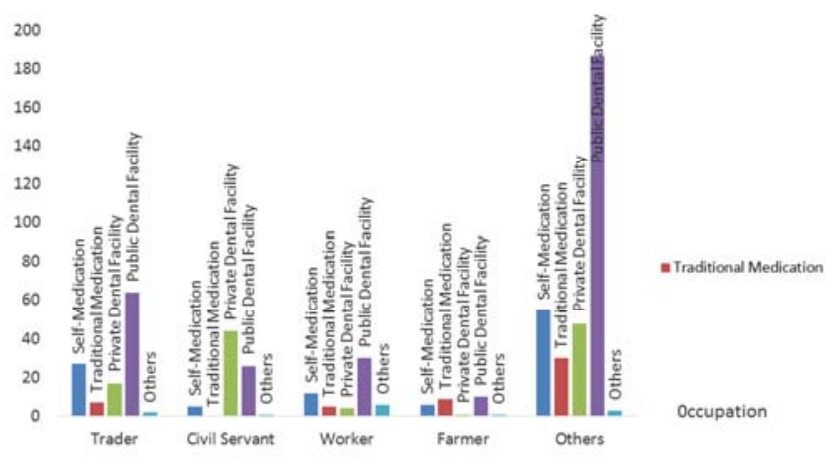

Fig. 3. Use of care services according to occupation.

Use of care services according to education

Patients who received high-school or university education go to public dental facilities and represent respectively $15 \%$ and $10 \%$ of the study population (Fig. 4 ).

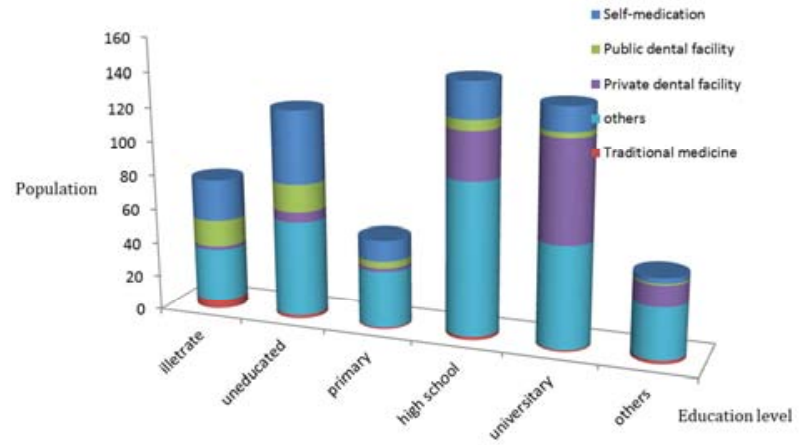

Fig. 4. Use of care services according to education.

Use of care services according to type of welfare:

$38 \%$ of the overall population goes to public dental facilities and themselves pay the care whereas $12.5 \%$ go to private ones and have a mutual health insurance (Fig. 5).

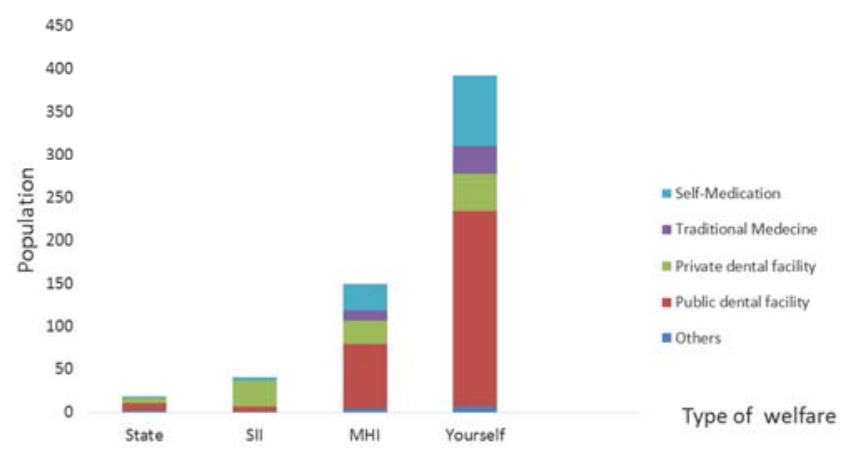

Fig. 5. Use of care services according to type of welfare.

\section{Discussion}

\subsection{Geographical Accessibility}

$26 \%$ of the survey population lives less than 5 kilometers away and 15\% live between 5 and 10 kilometers away from the nearest dental service and go to public dental facilities. There is an obvious impact of distance on consumption and this suggests there are not enough dental facilities in the country.

Several studies confirm our results, notably those of [Couffinal and coll] which show that the availability of care services has an impact on consumption as a low density of doctors causes a rise of care costs due to transport cost which is added, or due to the cost of the opportunity of the time related to the waiting period [6]. However, [Ould Taleb M. and coll.] show that a sick person living next to a health care facility prefers to go to a far remote one to receive care despite the transport cost and the travelling time, only because he or she will find there adequate care and quality health care services [7].

\subsection{Limitations of the Study}

The survey was planned to take place at a nationwide level, but due to budget restrictions and lack of time, it was finally carried out in the Dakar region and in its departments.

Despite our recommendation letter, the practitioners were not as cooperative as expected; especially in private practices, due to the important number of questionnaires we were supposed to give to the patients and which, according to the practitioners, contained confidential information about the patients themselves. Disclosing such information would be a violation of private life. This much impacted on the duration of the survey, which lasted longer than planned.

Some patients objected to answering questions about money and about civil status. As a result, we had to give up a few questionnaires and to submit the same number of questionnaires to other patients who were willing to answer them. This impacted on both the duration of the survey and the selection of the patients which was planned according to a step of 2 .

The survey sample is of an indicative nature, considering the time given and the budget we had at our disposal. Carried out in the Dakar region only, our survey cannot be absolute. However, it much informs about the consumption trend at the level of the national territory considering that the Dakar region concentrates more than $3 / 4$ of the country's dental facilities.

\subsection{Financial Accessibility}

The individuals who have no source of income or only one source of income tend to go to the public dental facilities, with a percentage of $17 \%$ and $34 \%$ respectively. Those who go to the private ones and who have only one source of income represent $9 \%$; whereas those who have two sources of income represent $3.6 \%$. The individuals who renounce care are those who have no source of income or only one source of income, with respectively $17 \%$ and $36.5 \%$. [Renahy and coll.] stated in their 2011 report that the limited income of the population accounts for the latter's use of the least onerous care possible [8].

The patients who have a monthly income lower than $50,000 \mathrm{Fcfa}$ or between 50,000 and 100,000 Fcfa go to public dental facilities and represent respectively $21 \%$ and $21.5 \%$, whereas the patients whose income is between 100,001 and 
150,000 Fcfa tend to go to private dental facilities and represent $3.6 \%$. In addition, it is noticed that the patients who renounce care the most have a monthly income lower than $50,000 \mathrm{Fcfa}$ or earn between 50,000 and 100,000 Fcfa, with respectively $22 \%$ and $19 \%$.

The works of [Desprès C. and coll.] on renunciation for financial reasons as well as [P. Dourgnon]'s study confirm that the population's purchasing power influences their spending on oral health care and, as a result, significantly increases renunciation of care. Cessation rate regularly increases as income per consumption unit decreases $[9,10]$.

However, [Gobbers D.] has stated that between the $20 \%$ of the persons considered as poor and the $20 \%$ of the persons considered as rich, there is only a difference of $15 \%$ as far as the use of modern care services is concerned [11]. Economic considerations are not "the key" factor of exclusion of access to care except for people with low income or without income at all.

\subsection{Social and Economic Status}

As far as social and economic status is concerned, traders and others (students in most cases) go to public dental facilities, and they are the most representative categories with respectively $31 \%$ and $11 \%$. Civil servants go more to private facilities, and represent $7 \%$. The latter renounce care the most in addition to traders and others who represent $10 \%$. [Azogui-Levyand coll.] confirm in their study on oral health care seeking behaviors that the households of unskilled workers renounce care 1.8 times more frequently than the households of both executives and traders [12]. A study carried out in Indonesia by [Chernichovsky D. and coll.] on the use of health care services [13] confirm these results.

Furthermore, the patients who have a high-school or university level of education go to public dental facilities and represent respectively $15 \%$ and $10 \%$ of the study population. This very segment of the population has never renounced oral health care.

Education level is one of the determinants of oral health care consumption, as renunciation tends to concern social groups with a low education level. Similar results were found by [Dourgnon P. and coll.] in France where renunciation among people who have reached a higher level is $12 \%$ whereas people who are uneducated and who only have a primary school level of education respectively have a cessation rate of $15.3 \%$ and $13.8 \%$ [14].

As far as costs are concerned, people who have no social welfare tend to go to public dental facilities, with $38 \%$ and $12.5 \%$. It is noticed that people who themselves pay the care or who have a mutual health insurance tend more to renounce oral health care, with $37 \%$ and $15 \%$.

These results are comparable to those of [LO.C.M.MB. and coll.] who have shown that people who have no social welfare renounce 2.3 times more than those who have one [15]. A more recent study carried out by [Bayat F. and coll.] in 2006 has shown that having welfare makes access to care easier [16].

However, studies by Darmon J. on health care spending and care renunciation make it clear that if a good complementary health cover definitely limits renunciation to care for financial reasons, major differences exist between social groups at a given level of insurance [17].

\section{Conclusion}

The distance between the living place and the heath care facility, the type of job, the level of education, the monthly income and the type of medical care, are the factors that influence Senegalese people's use of oral health care services. To improve this use and to overcome the obstacles related to the resort to oral health care, it is important to rely on our populations' innovative forms of organizations, such as women's groups (groups of 10 to 20 women), which receive funding to develop economic activities; dahiras, which are religion-based self-help and solidarity associations of men and women; sporting, cultural associations, and economic interest groups.

\section{Abbreviations}

USD: United States Dollars

GDP: Gross Domestic Product

SPSS: Statistical Package for Social Sciences

FCFA: Franc des Colonies Françaises d'Afrique

\section{Competing Interest}

Author Cheikh Mouhamadou Mbacke Lo, author Mbathio Diop, author Daouda Faye, author Aida Kanoute, author Massamba Diouf, author Daouda Cisse, declare that they have no competing interest.

\section{Authors' Contributions}

a) CMML contributed to the conception and design, the acquisition, analysis and interpretation of data; was involved in drafting the manuscript and revising it critically for important intellectual content. He gave final approval of the version to be published; agreed to be accountable for all aspects of the work in ensuring that questions related to the accuracy or integrity of any part of the work are appropriately investigated and resolved.

b) $\mathrm{BD}$ contributed to the conception and design, the acquisition, analysis and interpretation of data; was involved in drafting the manuscript and revising it critically for important intellectual content. He gave final approval of the version to be published; agreed to be accountable for all aspects of the work in ensuring that questions related to the accuracy or integrity of any part of the work are appropriately investigated and resolved.

c) DF contributed to the conception and design, the acquisition, analysis and interpretation of data; was involved in drafting the manuscript and revising it 
critically for important intellectual content. He gave final approval of the version to be published; agreed to be accountable for all aspects of the work in ensuring that questions related to the accuracy or integrity of any part of the work are appropriately investigated and resolved.

d) AK contributed to the conception and design, the acquisition, analysis and interpretation of data; was involved in drafting the manuscript and revising it critically for important intellectual content. He gave final approval of the version to be published; agreed to be accountable for all aspects of the work in ensuring that questions related to the accuracy or integrity of any part of the work are appropriately investigated and resolved.

e) MD contributed to the conception and design, the acquisition, analysis and interpretation of data; was involved in drafting the manuscript and revising it critically for important intellectual content. He gave final approval of the version to be published; agreed to be accountable for all aspects of the work in ensuring that questions related to the accuracy or integrity of any part of the work are appropriately investigated and resolved.

f) DC contributed to the conception and design, the acquisition, analysis and interpretation of data; was involved in drafting the manuscript and revising it critically for important intellectual content. He gave final approval of the version to be published; agreed to be accountable for all aspects of the work in ensuring that questions related to the accuracy or integrity of any part of the work are appropriately investigated and resolved.

\section{References}

[1] Chambaretaud S, Hartmann L. Economie de la sante: avancees theoriques et operationnelles. Rev. OFCE. 2004. n 91:237-268.

[2] Doumbouya L. Pauvrete et accessibilite aux services de sante: le cas de la Guinee. Economie et solidarites. 2007. vol. 38.n 2:137-153.

[3] Agence Nationale de Statistique et de Demographie: Enquête Demographique et de Sante Continue au Senegal. Rapport ANSD. Juillet 2013.
[4] Yam A. A. et coll. La carie dentaire: maladie infectieuse d'origine bacterienne. Journal dentaire du Quebec. 1997;n 44:321.

[5] Desprès C, Dourgnon P, Fantin R, Jusot F. Le renoncement aux soins pour raisons financières: approche econometrique. Question d'economie de la sante 2011;n 170:2-6.

[6] Couffinhal A, Dourgnon P, Geoffard P. Y. Les determinants des inegalites sociales de sante et le rôle du système de sante. Question d'economie de la sante. Fev 2005;n 92.

[7] OuldTaleb M, Schelling E, Essane S, et al. Le desert existe aussi dans la ville: regards sur la lutte contre la maladie chez les populations defavorisees en milieu peri urbain de Nouakchott. Revue electronique en sciences de l'environnement. 2006;n 3:13.

[8] Renahy E. Le renoncement aux soins pour raisons financières dans l'agglomeration parisienne. Rapport final DREES. 2011;n 10.

[9] Desprès C, Dourgnon P, Fantin R, Jusot F. Le renoncement aux soins: une approche socio-anthropologique. Question d'economie de la sante. 2011;n 169.

[10] Dourgnon P. Le renoncement aux soins pour raisons financières: une approche econometrique. Rapport final DREES. 2011;9-19.

[11] Gobbers D. L'equite dans l'accès aux soins en Afrique de l'Ouest. Adsp. 2002;n 38:71-77.

[12] Azogui-Levy S, Rochereau T, Gremy I. Comportement de recours aux soins et sante bucco-dentaire.Question d'economie de la sante. Mai 2005. n 24.

[13] Chernichovsky D, Meessook O. Utilization of Health Services in Indonesia. SocSci Med. 1986;n 23:20-611.

[14] Dourgnon P, Desprès C, Jusot F, Fantin R. Depense de sante et accès financier aux services de sante: une etude du renoncement aux soins. Document de travail de la Drees. Sept 2011;n 161:85-96.

[15] Lo C. M. M., CisseD., Faye D., FayeB., SarrM., Diallo P.D. Facteurs associes au renoncement aux soins bucco-dentaires au Senegal.ASPBD. 2010;n 1:8-12.

[16] Bayat F, Vehkalahti M. M, Zafarmand A. H.Dental Attendance Insurance Status among Adults in Teheran, Iran.Int Dent J. Dec 2006. vol: 56, n 6:338-44.

[17] Darmon, J. Depense de sante et renoncement aux soins. Comptes nationaux de la sante. 2010;85-94. 